\title{
Caracterização de argilas provenientes de indústria de cerâmica vermelha do Município do Crato - Ceará, Brasil
}

\author{
Characterization of clays from the red ceramic industry in the City of Crato - Ceará, Brazil \\ Caracterización de arcillas de la industria cerámica roja del Municipio de Crato - Ceará, Brasil
}

Recebido: 19/07/2021 | Revisado: 25/07/2021 | Aceito: 12/08/2021 | Publicado: 15/08/2021

\author{
Magno de Lima Silva \\ ORCID: https://orcid.org/0000-0002-9250-6230 \\ Universidade Federal do Cariri, Brasil \\ E-mail:magnolima9@gmail.com \\ Francisca Maria Martins Pereira \\ ORCID: https://orcid.org/0000-0002-8477-8922 \\ Universidade Federal do Cariri, Brasil \\ E-mail: francisca.martins@ufca.edu.br
}

\begin{abstract}
Resumo
Dentre os inúmeros produtos cerâmicos, destacam-se os produtos de cerâmica vermelha, também conhecidos no Brasil como cerâmica estrutural, usados na construção civil. A matéria-prima para a produção da cerâmica vermelha é a argila, mineral de baixo custo, proveniente da desintegração de rochas. A indústria de cerâmica vermelha é uma atividade econômica muito importante devido a geração de emprego e renda para a região do Cariri. Desse modo, a fim de se obter um melhor entendimento das propriedades dos materiais argilosos utilizados e determinar condições ideais para fabricação de diferentes tipos de peças cerâmicas com os mesmos, essa pesquisa teve como objetivo caracterizar três argilas coletadas em uma indústria cerâmica situada no município do Crato-CE. As amostras foram previamente beneficiadas por processos de britagem, moagem, peneiramento e secas em estufa a $110^{\circ} \mathrm{C}$. Em seguida, suas características foram avaliadas pelas seguintes técnicas: fluorescência de raios X (FRX), espectroscopia de infravermelho com transformada de Fourier (FTIR) e microscopia eletrônica de varredura (MEV). Os resultados indicaram altos teores de $\mathrm{SiO}_{2}, \mathrm{Al}_{2} \mathrm{O}_{3}$ e $\mathrm{Fe}_{2} \mathrm{O}_{3}$ para todas as argilas, bem como elevadas porcentagens do óxido fundente $\mathrm{K}_{2} \mathrm{O}$ para as argilas $\mathrm{A}_{2}$ e $\mathrm{A}_{3}$; diferentes vibrações $\mathrm{Al}_{2}-\mathrm{OH}, \mathrm{Si}-\mathrm{O}$, Si-O-Al e Si-OH características dos grupos funcionais pertencentes às estruturas dos argilominerais; grãos de formas lamelares e arredondadas, aglomeradas e dispersas; e concentrações próximas ao $100 \%$, de frações menores que $2 \mu \mathrm{m}$ para todas as amostras. De forma geral as argilas mostraram potencial para produção de telhas, tijolos e blocos cerâmicos desde que haja rigoroso controle de granulometria.
\end{abstract}

Palavras-chave: Argila; Caracterização; Cerâmica vermelha.

\begin{abstract}
Among the numerous ceramic products, red ceramic products, also known in Brazil as structural ceramics, used in civil construction stand out. The raw material for the production of red ceramics is clay, a low-cost mineral that comes from the disintegration of rocks. The red ceramic industry is a very important economic activity due to the generation of jobs and income for the Cariri region. Thus, in order to obtain a better understanding of the properties of the clay materials used and to determine ideal conditions for the manufacture of different types of ceramic pieces with them, this research aimed to characterize three clays collected in a ceramic industry located in the municipality of Crato-CE. The samples were previously processed by crushing, grinding, sieving and kiln dried at $110^{\circ} \mathrm{C}$. Then, its characteristics were evaluated by the following techniques: X-ray fluorescence (FRX), Fourier transform infrared spectroscopy (FTIR) and scanning electron microscopy (SEM). The results indicated high levels of $\mathrm{SiO}_{2}, \mathrm{Al}_{2} \mathrm{O}_{3}$ and $\mathrm{Fe}_{2} \mathrm{O}_{3}$ for all clays, as well as high percentages of $\mathrm{K}_{2} \mathrm{O}$ melting oxide for clays $\mathrm{A}_{2}$ and $\mathrm{A}_{3}$; different $\mathrm{Al}_{2}-\mathrm{OH}$, Si-O, Si-O-Al and Si-OH vibrations characteristic of the functional groups belonging to the clay mineral structures; grains of lamellar and rounded shapes, agglomerated and dispersed; and concentrations close to $100 \%$, of fractions less than $2 \mu \mathrm{m}$ for all samples. In general, clays showed potential for the production of tiles, bricks and ceramic blocks provided there is strict control of granulometry.
\end{abstract}

Keywords: Clay; Characterization; Red ceramic.

\section{Resumen}

Entre los innumerables productos cerámicos, se destacan los productos cerámicos rojos, también conocidos en Brasil como cerámicas estructurales, utilizados en la construcción civil. La materia prima para la producción de cerámica roja 
es la arcilla, un mineral de bajo costo que proviene de la desintegración de rocas. La industria de la cerámica roja es una actividad económica muy importante debido a la generación de empleo e ingresos para la región de Cariri. Así, con el fin de obtener un mejor conocimiento de las propiedades de los materiales arcillosos utilizados y determinar las condiciones ideales para la fabricación de diferentes tipos de piezas cerámicas con ellos, esta investigación tuvo como objetivo caracterizar tres arcillas recolectadas en una industria cerámica ubicada en el municipio de Crato-CE. Las muestras fueron previamente procesadas mediante trituración, molienda, tamizado y secado al horno a $110{ }^{\circ} \mathrm{C}$. Posteriormente, se evaluaron sus características mediante las siguientes técnicas: fluorescencia de rayos X (FRX), espectroscopía infrarroja por transformada de Fourier (FTIR) y microscopía electrónica de barrido (SEM). Los resultados indicaron altos contenidos de $\mathrm{SiO}_{2}, \mathrm{Al}_{2} \mathrm{O}_{3}$ y $\mathrm{Fe}_{2} \mathrm{O}_{3}$ para todas las arcillas, así como altos porcentajes de óxido fundente $\mathrm{K}_{2} \mathrm{O}$ para las arcillas $\mathrm{A}_{2}$ y $\mathrm{A}_{3}$; diferentes vibraciones $\mathrm{Al}_{2}-\mathrm{OH}$, Si-O, Si-O-Al y Si-OH características de grupos funcionales pertenecientes a estructuras minerales arcillosas; granos con formas lamelares y redondeadas, aglomerados y dispersos; y concentraciones cercanas al $100 \%$, de fracciones menores a $2 \mu \mathrm{m}$ para todas las muestras. En general, las arcillas mostraron potencial para la producción de tejas, ladrillos y bloques cerámicos siempre que exista un estricto control granulométrico.

Palabras clave: Arcilla; Caracterización; Cerámica roja.

\section{Introdução}

As argilas podem ser tidas como um material natural de textura terrosa, granulação fina, constituída essencialmente de argilominerais como caulinita, haloisita, entre outros, podendo também conter outros minerais (quartzo, mica, pirita, hematita, etc.), matéria orgânica e impurezas. Os argilominerais são os minerais característicos das argilas e fornecem a elas algumas de suas características específicas como plasticidade, compactação, resistência mecânica após a secagem e queima (ABCERAM, 2016).

Os argilominerais ou minerais de argila estão agrupados, em sua maioria, dentro do grupo ou família dos filossilicatos; quimicamente esses minerais são silicatos de alumínio ou magnésio hidratados, podendo conter certos tipos de elementos como ferro, potássio, lítio e outros. Além disso, possuem estrutura em folhas tetraédricas e octaédricas bidimensionais e contínuas que facilitam os deslizamentos, ou seja, gerando plasticidade.

Apesar do grande número de tipos de argilominerais, há alguns de maior interesse para a indústria cerâmica, são eles os principais grupos: caulinita $\left[\mathrm{Al}_{4} \mathrm{Si}_{4} \mathrm{O}_{10}(\mathrm{OH})_{8}\right]$, esmectita $\left[\mathrm{Al}_{4} \mathrm{Si}_{8} \mathrm{O}_{20}(\mathrm{OH})_{4} \mathrm{nH}_{2} \mathrm{O}\right]$ e ilita (Moreno, 2010).

Dessa forma, várias são as aplicações tecnológicas encontradas para as argilas, o uso da argila na indústria pode ser feito nos mais diversos segmentos como na petroquímica podendo ser utilizadas na produção de gasolina e como descorante de óleo. Na indústria farmacêutica é usada para tratamento cicatrizante e desintoxicação celular, na indústria automobilística através de peças e segmentos constituintes dos itens necessários para fabricação de veículos automotores e para o tratamento de efluentes industriais contendo metais pesados, adsorvendo íons de chumbo, cádmio, cromo, zinco, níquel e cobre (Bezerra, 2012; Caetano, 2015).

Na construção civil a argila é utilizada para confecção de blocos, pisos, tubos e telhas cerâmicas bem como para fabricação de utensílios domésticos como cubas de pias ou lavabos, aparelhos sanitários e demais objetos aplicados à decoração do imóvel. O uso da argila na confecção de blocos, pisos e telhas é realizado pelo segmento industrial denominado de indústria de cerâmica vermelha, sendo este uso mais tradicional tendo em vista que a fabricação de blocos cerâmicos já era realizada desde tempos remotos de nossa civilização (Bezerra, 2012).

Atualmente a cerâmica de construção brasileira ocupa um lugar de destaque na economia do país, com um número aproximado de 7 mil olarias e cerâmicas de pequeno e médio porte, em que são gerados 293 mil empregos diretos e cerca de 900 mil empregos indiretos (ANICER, 2019).

Em 2012, o Sindicato das Indústrias de Cerâmica do Estado do Ceará (SINDICERÂMICA) se associou ao Instituto Euvaldo Lodi (IEL) - CE e com apoio do Banco do Nordeste (BNB) realizaram um diagnóstico socioeconômico da indústria de 
cerâmica vermelha do estado do Ceará. O estudo mostrou que havia 412 fábricas em funcionamento nesse ano, distribuídas em 93 municípios do estado (Prado, 2017).

A indústria cerâmica da região do Cariri possui uma gestão familiar, se caracterizando como uma indústria nativa, devido à presença de olarias e pequenas empresas. Existem aproximadamente 30 fábricas. Ela é grande consumidora de matériasprimas minerais e possui uma grande diversidade dos mesmos, sendo que depende de onde está localizada a fábrica e o tipo de produto (Neta et al., 2016). Os principais produtos sul-cearenses de cerâmica vermelha são tijolos de oito furos e telhas, totalizando, no ano de 2012, 25 milhões de peças/mês (Prado, 2017).

Macêdo et al. (2012) em seu estudo sobre as olarias da microrregião do Cariri (pertencente a mesorregião sul do estado do Ceará) afirmam que as mesmas contribuem para o desenvolvimento econômico e social, porém é preciso ter maior conhecimento sobre suas matérias-primas, características tecnológicas e condições para o reaproveitamento de seus resíduos.

Nesse contexto, essa pesquisa teve como objetivo caracterizar química, física e morfologicamente três argilas coletadas em uma indústria cerâmica situada no município do Crato-CE de forma a se obter um melhor entendimento das propriedades desses materiais argilosos e assim, determinar condições ideais para fabricação de diferentes tipos de peças cerâmicas com os mesmos.

\section{Metodologia}

A pesquisa foi conduzida através de um estudo quantitativo e experimental (Dalfovo, Lana \& Silveira, 2008). Três argilas provenientes de uma indústria cerâmica localizada no município do Crato, na região do Cariri-CE foram coletadas, acondicionadas em saco plástico, codificadas $\left(\mathrm{A}_{1}, \mathrm{~A}_{2}\right.$ e $\left.\mathrm{A}_{3}\right)$, conforme mostrado na Figura 1, e transportadas até o Laboratório de Materiais Cerâmicos da Universidade Federal do Cariri (UFCA).

Devido as amostras terem sido recolhidas ainda com tamanho grosseiro, as mesmas foram britadas utilizando uma marreta, onde se diminuiu seu tamanho de partícula o suficiente para que fosse levado até o moinho de rotor a martelo Servitech Equipamentos Cerâmicos/CT-058. O material resultante da moagem foi passado em peneira Associação Brasileira de Normas Técnicas $(\mathrm{ABNT}) 200$ mesh (diâmetro de abertura $=75 \mu \mathrm{m}$ ) e levado para secagem em estufa Fanem ltda 520 por um período de $24 \mathrm{~h}$ na temperatura de $110^{\circ} \mathrm{C}$. Em seguida, as amostras foram transferidas para o Laboratório de Caracterização de Materiais da UFCA para verificação de suas características químicas, físicas e morfológicas.

Figura 1. Amostra de argila para caracterização.

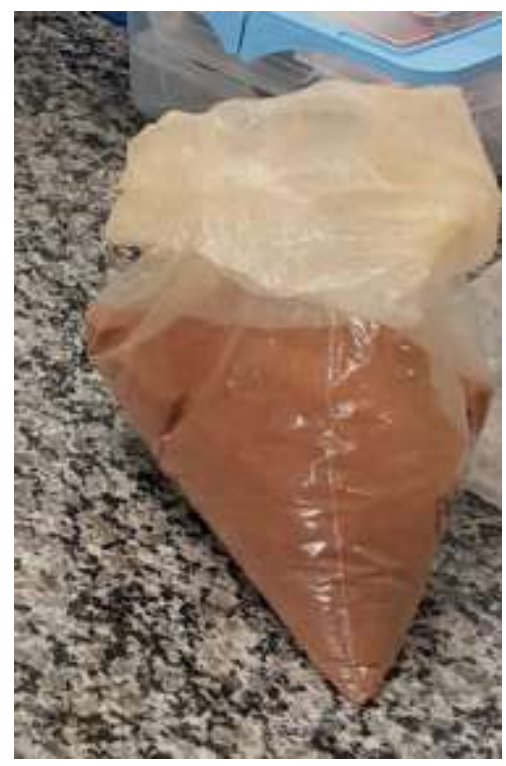

Fonte: Dados da Pesquisa (2021). 
Para determinação da composição química das argilas, empregou-se a técnica de fluorescência de raios X (FRX) em equipamento PANalytical Epsilon 1 equipado com ânodo de prata e tensão de $50 \mathrm{keV}$.

Os espectros vibracionais na região do infravermelho foram obtidos em um espectrofotômetro FTIR Perkin Elmer modelo Spectrum Two, sendo registrados entre 400 e $4000 \mathrm{~cm}^{-1}$ com resolução de $3 \mathrm{~cm}^{-1}$ e modo de operação por pastilhas de $\mathrm{KBr}$.

A morfologia das amostras foi determinada utilizando-se um Microscópico Eletrônico de Varredura (MEV), Tescan Vega 3 com operação a $30 \mathrm{kV}$ e contraste de elétrons retroespalhados. As amostras foram colocadas sobre a superfície do suporte com fita de carbono dupla face e cobertas com uma fina camada de ouro.

A análise granulométrica foi realizada por meio de medição do diâmetro de Ferret das partículas visualizadas nas fotomicrografias obtidas por MEV com aumentos de 1000x $\left(\mathrm{A}_{1}\right.$ e $\left.\mathrm{A}_{2}\right)$ e 2000x ( $\left.\mathrm{A}_{3}\right)$ utilizando o software Image-Pro 10. O número de partículas contadas foi de 144 para a argila $\mathrm{A}_{1}, 344$ para $\mathrm{A}_{2}$ e 160 para $\mathrm{A}_{3}$. A partir desses dados foram construídos os histogramas de distribuição de tamanho de partículas em função da frequência, os quais foram ajustados a uma distribuição de erro normal.

\section{Resultados e Discussão}

\subsection{Fluorescência de raios X (FRX)}

Os resultados das análises químicas (Tabela 1) indicam que todas as argilas possuem predominância de $\mathrm{SiO}_{2}$ e $\mathrm{Al}_{2} \mathrm{O}_{3} \mathrm{e}$ $\mathrm{Fe}_{2} \mathrm{O}_{3}$. Esses teores são característicos de argilas empregadas na confecção de produtos de cerâmica vermelha (Suassuna, Cartaxo \& Brasileiro, 2013).

Tabela 1. Análise química das amostras de argilas (\% massa).

\begin{tabular}{cccc}
\hline Óxidos & $\mathbf{A}_{\mathbf{1}}$ & $\mathbf{A}_{\mathbf{2}}$ & $\mathbf{A}_{\mathbf{3}}$ \\
\hline $\mathrm{SiO}_{2}$ & 23,71 & 30,99 & 27,56 \\
$\mathbf{A l}_{2} \mathbf{O}_{3}$ & 14,06 & 14,61 & 12,59 \\
$\mathbf{K}_{2} \mathbf{O}$ & 0,59 & 4,63 & 5,93 \\
$\mathbf{C a O}$ & 0,25 & - & 1,06 \\
$\mathbf{T i O}_{2}$ & 0,79 & 0,85 & 1,03 \\
$\mathbf{F e}_{2} \mathbf{O}_{3}$ & 10,63 & 26,15 & 18,24 \\
$\mathbf{M n O}_{\mathbf{P}_{2} \mathbf{O}_{5}}$ & 0,01 & 0,11 & 0,07 \\
$\mathbf{C l}_{2} \mathbf{O}$ & 0,84 & 0,80 & 0,79 \\
\hline
\end{tabular}

Fonte: Dados da Pesquisa (2021).

Como pode ser observado na Tabela 1 foram encontradas elevadas quantidades de óxido de silício, de acordo com Dutra et al. (2005) essas quantidades podem estar associadas à presença de quartzo, caulinita, entre outros argilominerais principalmente. Cartaxo et al. (2015) explicam que nestas proporções podem diminuir a plasticidade das massas, e influenciar de forma positiva na permeabilidade e na estabilidade dimensional dos corpos de prova.

Os percentuais de $\mathrm{Al}_{2} \mathrm{O}_{3}$ apresentados estão em concordância com os estudos feitos por Suassuna, Cartaxo \& Brasileiro (2013) e Cartaxo et al. (2015) que obtiveram resultados próximos na faixa de $23,17 \%-26,71 \%$ e $24,04 \%-26,09 \%$ respectivamente para argilas da mesma região. Santos (1989) ressalta que o alumínio existente numa argila está em sua maior parte combinado formando os argilominerais, geralmente a caulinita.

Segundo Maestrelli et al. (2013), a elevada presença de $\mathrm{Fe}_{2} \mathrm{O}_{3}\left(\mathrm{~A}_{1}-10,63 \% ; \mathrm{A}_{2}-26,15 \%\right.$ e $\left.\mathrm{A}_{3}-18,24 \%\right)$ encontradas nas argilas, pode contribuir para a formação de eutéticos de baixo ponto de fusão. Dutra et al. (2005) expõem que o óxido de 
ferro tem efeito na alteração da cor da argila quando queimada e na redução da refratariedade. Silva et al. (2011) reportam que o óxido de ferro pode ser encontrado em argilas na forma de magnetita $\left(\mathrm{F}_{3} \mathrm{O}_{4}\right)$ e hematita $\left(\mathrm{F}_{2} \mathrm{O}_{3}\right)$ sendo que as mesmas apresentam coloração avermelhada quando o ferro está presente na forma de hematita e cor preta quando na forma de magnetita.

Os baixos teores de $\mathrm{TiO}_{2}$ encontrados estão próximos aos teores encontrados por Neta et al. (2016) em seu estudo de caracterização química de argilas da indústria cerâmica do Cariri cearense $(0,96 \% ; 0,85 \%$ e $0,75 \%)$. Dutra et al. (2005) esclarecem que o titânio, normalmente em forma de rutilo, anatase ou impurezas de outros minerais, apresenta-se em porcentagens inferiores a $2 \%$ e mesmo em pequenas quantidades pode ser um agente de variação de tonalidade.

Segundo Reis et al. (2014a), a concentração de fundentes tais como $\mathrm{K}_{2} \mathrm{O}$ e $\mathrm{Na}_{2} \mathrm{O}$, atuam no sentido melhorar a vitrificação dos materiais cerâmicos. Como pode ser observado a concentração de $\mathrm{K}_{2} \mathrm{O}$ foi elevada para as amostras $\mathrm{A}_{2}$ e $\mathrm{A}_{3}$, e baixo para a amostra $\mathrm{A}_{1}$. Enquanto que nenhuma das amostras estudadas apresentaram a presença de $\mathrm{Na}_{2} \mathrm{O}$, semelhante ao estudo de Menezes et al. (2009) que caracterizou argilas bentoníticas da região nordeste do Brasil. Santos (1989), enfatiza que os álcalis $\mathrm{Na}_{2} \mathrm{O}$ e $\mathrm{K}_{2} \mathrm{O}$ encontrados nas argilas são quase que totalmente devido a feldspatos, micas ou cátions trocáveis. Contribuem para a formação da fase líquida durante o processo de queima e podem reagir formando fases cristalinas mais estáveis mediante a umidade (Facincani, 1993 apud Neta et al., 2016).

Para Santos (1989), óxidos de cálcio são agentes fundentes e tendem a baixar a refratariedade das argilas, ao passo que o cálcio é um elemento pouco encontrado em argilas brasileiras devido ao elevado grau de intemperismo no Brasil. O que justifica as mínimas porcentagens de $\mathrm{CaO}$ encontradas em $\mathrm{A}_{1}$ e $\mathrm{A}_{3}$ e a inexistência de óxidos desse elemento na argila $\mathrm{A}_{2}$.

\subsection{Espectroscopia de infravermelho com transformada de Fourier (FTIR)}

Na Figura 2 são apresentados os espectros de FTIR das argilas $A_{1}, A_{2}$ e $A_{3}$. Observa-se que de certa forma, os espectros dessas argilas são bem semelhantes principalmente no que diz respeito aos estiramentos exibidos em 3620, 1636 e $693 \mathrm{~cm}^{-1}$ presentes nas três amostras.

Segundo Mariani, Villalba e Anaissi (2013), os modos vibracionais nas bandas localizadas em $3620 \mathrm{~cm}^{-1}$ são atribuídos à deformação axial de hidroxila estrutural $\mathrm{Al}_{2}-\mathrm{OH}$. E as bandas por volta de $693 \mathrm{~cm}^{-1}$ são características do quartzo (Carrera, Varajão \& Gonçalves, 2008).

As bandas a $1636 \mathrm{~cm}^{-1}$, possivelmente se referem à vibração de estiramento e de deformação de água de hidratação (Carrera, Varajão \& Gonçalves, 2008) entretanto, esta apresenta-se menos intensa nas argilas $A_{1}$ e $A_{2}$ se comparado com $A_{3}$ indicando maior quantidade de água na estrutura dessa última. As bandas em 3431 e $3429 \mathrm{~cm}^{-1}$ nas argilas $\mathrm{A}_{2}$ e $\mathrm{A}_{3}$, respectivamente, correspondem à deformação axial da água de hidratação (Porto \& Aranha, 2002).

As bandas de absorção em 3696, 3697 e 3698 cm$^{-1}$ nas argilas são provavelmente relacionadas à caulinita (Carrera, Varajão \& Gonçalves, 2008). As bandas de absorção em 1034, 1032 e 912 cm-1 também são características desse argilomineral (Oliveira et al., 2016).

$\mathrm{Na}$ argila $\mathrm{A}_{1}$ a banda em $1099 \mathrm{~cm}^{-1}$ pode ser devida a vibração $\mathrm{Al}-\mathrm{OH}$ que possui vibrações por volta de $1100 \mathrm{~cm}^{-1}$. Em $3650 \mathrm{~cm}^{-1}$ pode ser indicativo de um grau diferente de cristalinidade da caulinita (Silva \& Salvetti, 1999).

Silva e Salvetti (1999) esclarecem que os principais responsáveis pelo espectro de absorção dos argilominerais são as ligações de hidrogênio dos grupos estruturais $\mathrm{OH}$, as vibrações $\mathrm{Si}-\mathrm{O}$ e Al-O nas subcamadas tetraédricas e octaédricas e outros óxidos minerais associados. Rossetto et al. (2009) em seu estudo, indicam que podem ser observadas entre 600 e $1500 \mathrm{~cm}^{-1}$ vibrações referentes à estrutura da montmorilonita. E que dentro dessa faixa, na região de $600-900 \mathrm{~cm}^{-1}$ ocorre diferentes vibrações Si-O e Si-O-Al.

Na Figura 2 são observadas bandas em 466, 468 e $469 \mathrm{~cm}^{-1}$ nas argilas, as quais denotam deformação angular Si-OH, corroborando com o estudo de Caetano (2015) que constatou vibrações Si-OH em 464 e $466 \mathrm{~cm}^{-1}$ para argilas bentonitas naturais. 
Nota-se para as amostras bandas em 532, 534 e $539 \mathrm{~cm}^{-1}$ que podem ser atribuídas à deformação angular Si-O-Al. Caetano (2015) reforça que deformação angular Si-O-Al em torno de $529 \mathrm{~cm}^{-1}$ se refere aos átomos de silício em sítio tetraédrico e aos átomos de alumínio em sítio octaédrico o que evidencia a presença de um argilomineral com folhas tetraédricas e octaédricas.

Porto e Aranha (2002) apontam deformações axiais da ligação Si-O da rede cristalina, fora do plano na faixa de 1010$1030 \mathrm{~cm}^{-1}$ e no plano, por volta de 1095-1110 cm-1. Já Oliveira (2016) específica as vibrações de ligação Si-O entre 912 e 794 $\mathrm{cm}^{-1}$ as quais correspondem às bandas características de camadas octaédricas de aluminosilicatos.

Neta et al. (2016) justificam que a constituição de argilas resultantes de jazimentos de cerâmica vermelha pode variar e que é possível que cada amostra apresente caráter particular mesmo estas sendo provenientes de uma mesma bacia hidrográfica.

Figura 2. Espectros de FTIR das argilas estudadas.

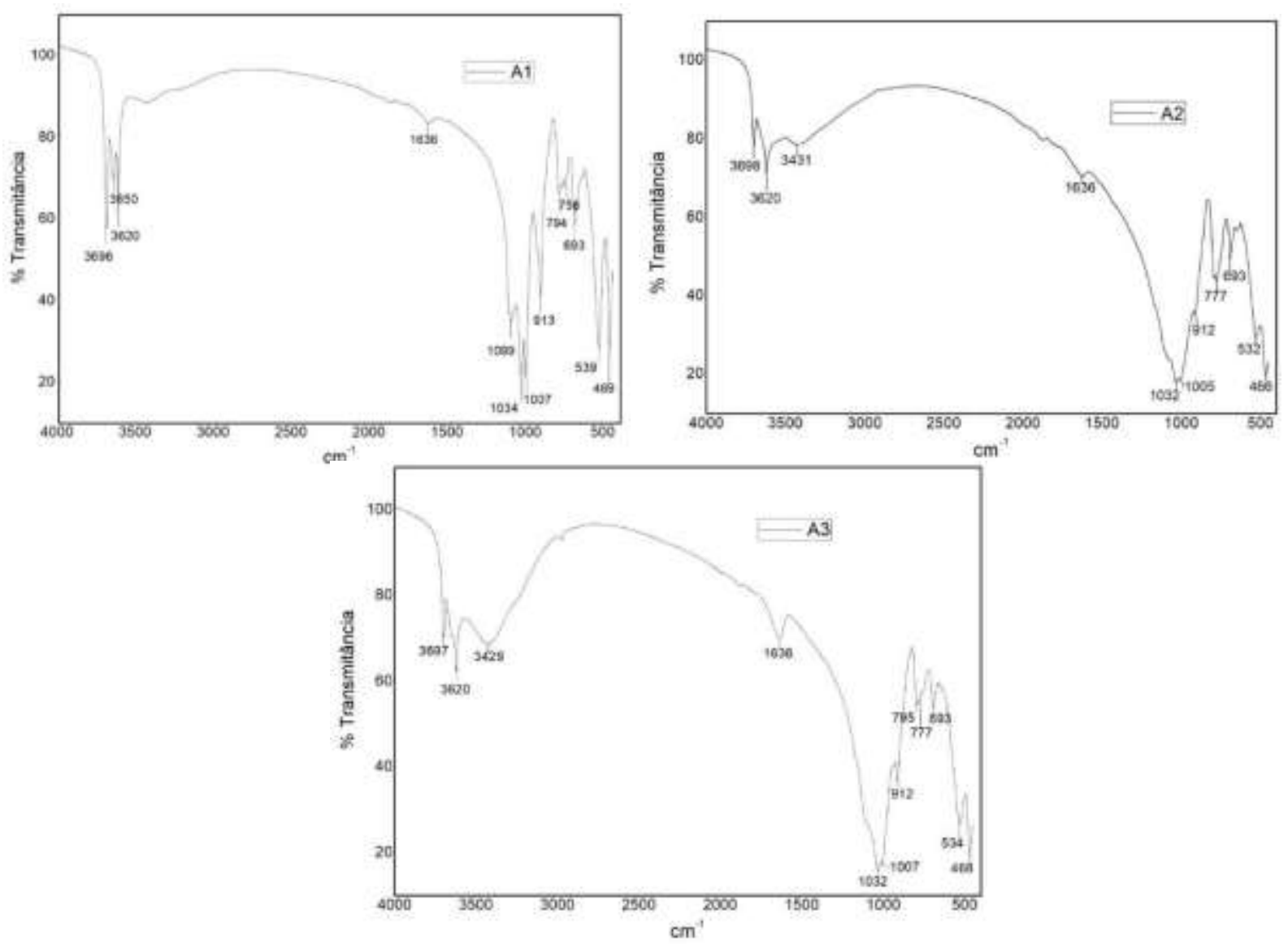

Fonte: Dados da Pesquisa (2021).

\subsection{Análise granulométrica}

Os histogramas de distribuição de tamanho de partículas das argilas são mostrados na Figura 3, onde é possível observar que as três amostras possuem maior concentração de partículas de tamanhos $<2 \mu \mathrm{m}$ "fração argila" ( $A_{1}-93,75 \%, A_{2}-98,83 \%$ e $A_{3}-100 \%$ ), sendo que $77,08 \%$ destas na argila $A_{1}$ estão na faixa de diâmetros de 0,04 a $0,72 \mu \mathrm{m} ; 68,89 \%$ em $\mathrm{A}_{2}$ de 0,03 a $0,23 \mu \mathrm{m} ; \mathrm{e} 81,25 \%$ em $\mathrm{A}_{3}$ de 0,01 a $0,13 \mu \mathrm{m}$. Indicativo de que as amostras possuem quantidades consideráveis de argilominerais. A maioria dos argilominerais, naturalmente, é constituída por partículas com algumas dimensões geralmente abaixo de $2 \mu \mathrm{m}$. Alguns destes podem conter uma fração com dimensões na faixa de 1 a $100 \mathrm{~nm}$, sendo nanométricos (Zaccaron, 2018).

Também se verifica mínimas concentrações de partículas "fração silte" para $A_{1}(6,25 \%)$ e $A_{2}(1,16 \%)$ estando possivelmente associadas a partículas finas de quartzo confirmadas pelas análises de FTIR. Para nenhuma das amostras foi 
detectada a "fração areia". Juntamente com as partículas de argilominerais ocorrem outros minerais geralmente nas frações silte (entre $2 \mu \mathrm{m}=0,002 \mathrm{~mm}\langle\phi>0,62 \mathrm{~mm})$ e areia $(\phi>0,62 \mathrm{~mm})$. Nessas granulometrias maiores, o mineral mais comum é o quartzo, seguido de micas, feldspatos e minerais opacos (Silva, 2008).

$\mathrm{O}$ diâmetro médio das partículas foi de $0,62 \mu \mathrm{m}$ para $\mathrm{A}_{1}$, variando de 0,04 a $6,7 \mu \mathrm{m} ; 0,26 \mu \mathrm{m}$ para $\mathrm{A}_{2}$, variando de 0,03 e 2,98 $\mu \mathrm{m}$; e 0,09 $\mu \mathrm{m}$ para $\mathrm{A}_{3}$ variando de 0,005 a 1,49 $\mu \mathrm{m}$. A argila $\mathrm{A}_{3}$ apresenta menor diâmetro médio de partícula, devido a distribuição de tamanho de partícula mais fina em relação às amostras $A_{2}$ e $A_{1}$. Porém, vale ressaltar que todas as matériasprimas passaram por processo de beneficiamento por moagem.

Maestrelli et al. (2013) especificam que granulometrias finas contribuem para maior sinterabilidade durante o processo de queima, devido à maior reatividade das partículas. E ainda podem ajudar no empacotamento (aumentando a densidade da peça), auxiliando na resistência mecânica do material cerâmico (Zaccaron, 2018).

Zaccaron (2018) afirma que uma argila para fabricação de cerâmica vermelha, dificilmente é composta majoritariamente por grãos menores que $2 \mu \mathrm{m}$, e sim, por um composto de material com faixa de grãos inferiores a $2 \mu \mathrm{m}$, ou seja, argila, e superiores a $2 \mu \mathrm{m}$, que são os siltes e a areia.

Os produtos de cerâmica vermelha (tijolos manuais e prensados, tijolos furados e telhas) estão diretamente relacionados com as composições granulométricas do diagrama de Winkler nas faixas $<2 \mu \mathrm{m}, 2$ a $20 \mu \mathrm{m}$ e $>20 \mu \mathrm{m}$ (Riker, 2005). Considerando apenas esses valores as amostras $\left(\mathrm{A}_{1}, \mathrm{~A}_{2}\right.$ e $\left.\mathrm{A}_{3}\right)$ não seriam consideradas adequadas para fabricação desses produtos uma vez que não foram constatadas partículas com tamanhos maiores que $20 \mu \mathrm{m}$ e os teores na faixa de 2 a $20 \mu \mathrm{m}$ foram muito baixos. Dessa forma, essas devem ser possivelmente misturadas com uma ou mais matérias-primas para ajuste de granulometria.

Figura 3. Histogramas de distribuição granulométrica das argilas.
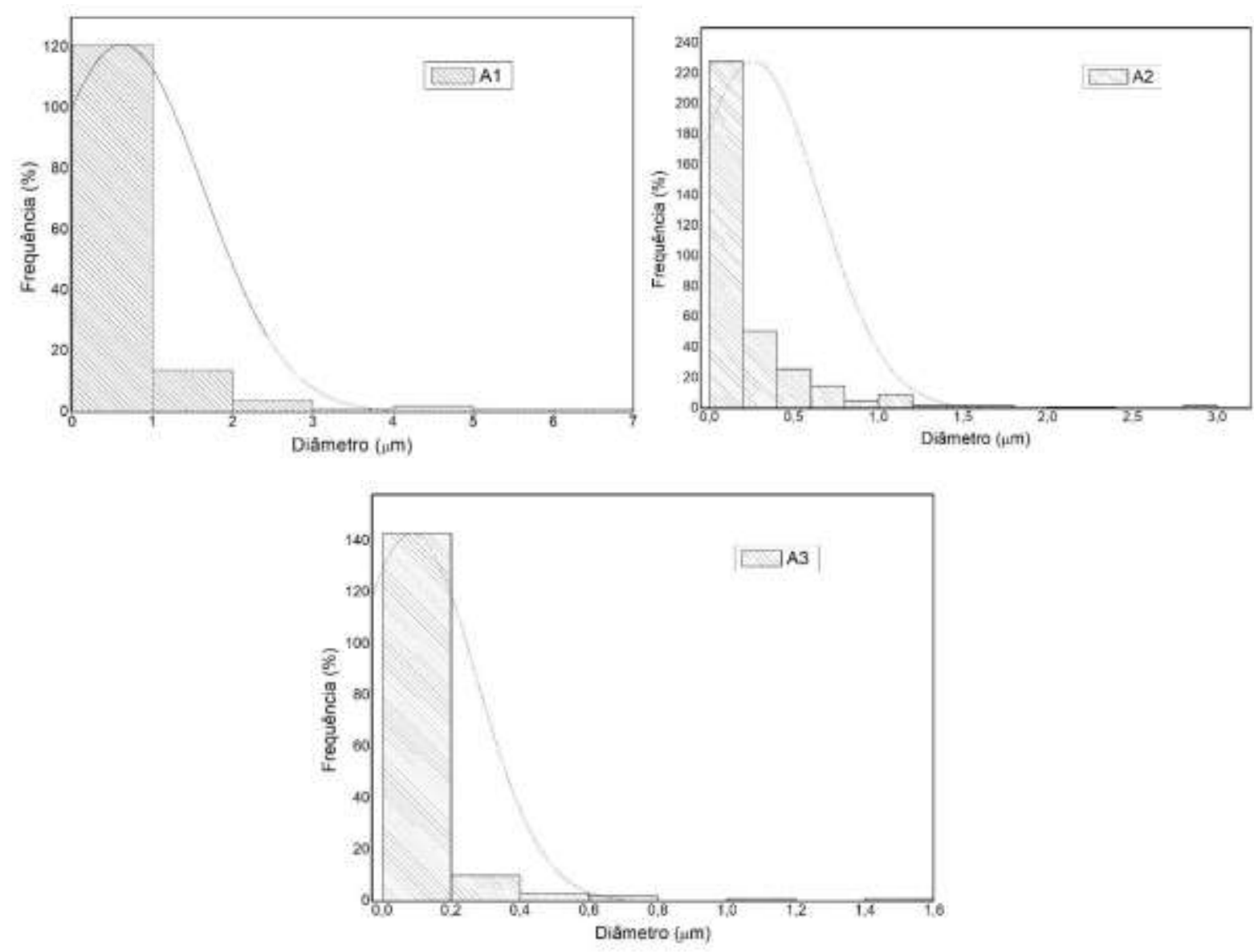

Fonte: Dados da Pesquisa (2021). 


\subsection{Microscopia eletrônica de varredura (MEV)}

A Figura 4 apresenta as micrografias das argilas. Observa-se que os grãos se apresentam em forma lamelar, algumas dispersas e outras aglomeradas. Formas essas adequadas para utilização em cerâmica vermelha estrutural (REIS et al., 2014b).

Aglomerados também foram evidenciados no trabalho de Tonnesen et al. (2012) que associam aqueles distribuídos na forma de pequenos grãos dispersos ao quartzo.

Segundo Caetano (2015) a formação de aglomerados é característica de argilominerais do grupo da esmectita, mais especificamente a montmorilonita. Ressalta ainda que partículas sobrepostas, chamado de sobreposição de lamelas, é característico de filossilicatos em camadas, como pode ser observado na Figura 4.

Menezes et al. (2009) relacionam essa disposição em aglomerados, bem como a elevada quantidade de partículas inferiores a 0,50-0,25 $\mu \mathrm{m}$ com a presença de aglomerados de argilominerais esmectíticos, sendo que as partículas lamelares de maiores dimensões estão provavelmente relacionadas a caulinita. Já as partículas anisométricas com arestas vivas, provavelmente são atribuídas às partículas de quartzo.

Ademais, Vilar et al. (2009) ao caracterizar uma argila natural da região nordeste constituída majoritariamente por esmectita, observou lamelas irregulares de diferentes tamanhos e presença de agregados não uniformes.

Na Figura 4 também podem ser vistos aglomerados laminares de partículas com bordas irregulares. De acordo com Ferreira (2010) aglomerados de bordas irregulares e formas arredondadas, resultante da aglomeração de partículas que também apresentam formato laminar, são característicos dos cristais de caulinita.

Figura 4. Micrografias das argilas $A_{1}$ e $A_{2}$ com aumentos de 1000x e $A_{3}$ com 2000x.

a) $\mathrm{A}_{1}$

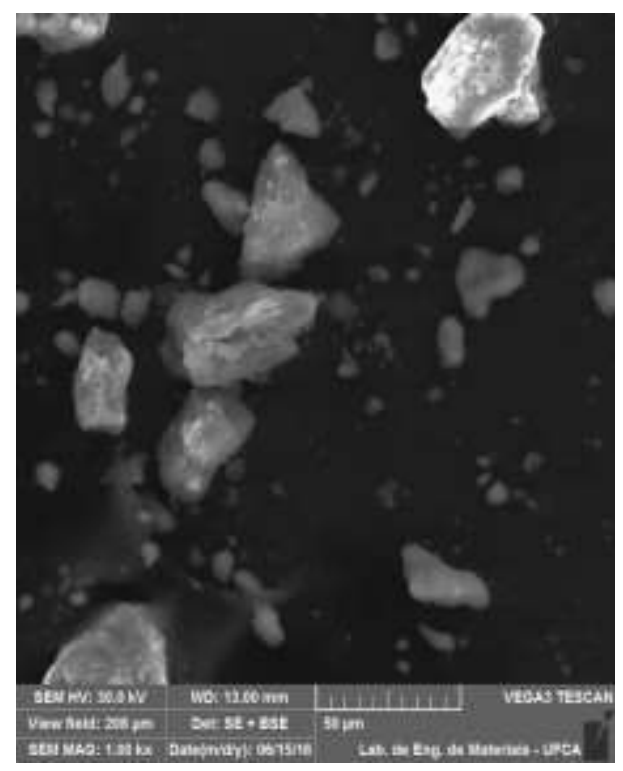

b) $\mathrm{A}_{2}$






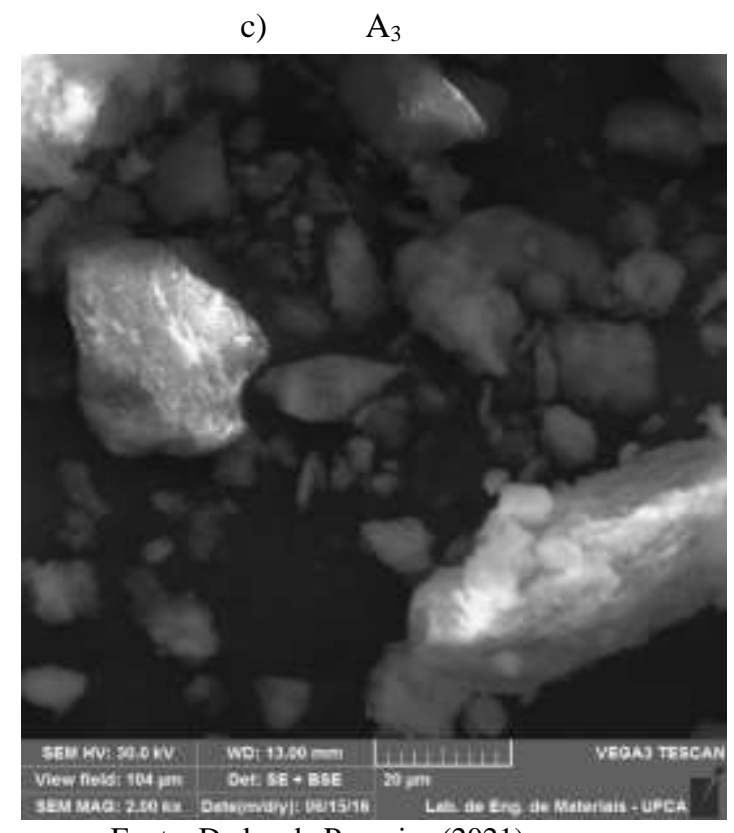

Fonte: Dados da Pesquisa (2021).

\section{Conclusão}

Todas as argilas apresentam em sua composição química altos teores de $\mathrm{SiO}_{2}, \mathrm{Al}_{2} \mathrm{O}_{3}$ e $\mathrm{Fe}_{2} \mathrm{O}_{3}$ característicos de argilas para cerâmica vermelha. O óxido de ferro com quantidades que conduzirão a cor vermelha aos materiais quando queimados. Além disso, as argilas denominadas $\mathrm{A}_{2}$ e $\mathrm{A}_{3}$ exibiram elevadas porcentagens do óxido fundente $\mathrm{K}_{2} \mathrm{O}$ o que favorecerá a formação de fase líquida no processo de queima, contribuindo para redução de poros e aumentando a densificação. Por outro lado, a argila $\mathrm{A}_{1}$ provavelmente apresentará maior temperatura de queima.

As análises de FTIR constataram diferentes vibrações $\mathrm{Al}_{2}-\mathrm{OH}$, Si-O, Si-O-Al e Si-OH características dos grupos funcionais pertencentes às estruturas dos argilominerais caulinita e montmorilonita, bem como do mineral quartzo. Além de água de hidratação nos materiais estudados.

As argilas possuem grãos de formas lamelares e arredondadas, aglomeradas e dispersas com aglomerados laminares de partículas com bordas irregulares.

A análise granulométrica confirmou elevadas concentrações, próximo ao $100 \%$, de frações menores que $2 \mu \mathrm{m}$ para todas as amostras, com baixos percentuais entre $2 \mu \mathrm{m}\langle\phi>0,62 \mathrm{~mm}$, não sendo detectado partículas $>0,62 \mathrm{~mm}$.

As argilas estudadas mostraram potencial para produzir aplicações industriais como telhas, tijolos e blocos cerâmicos devido a composição química com teores que atendem aos encontrados na literatura; a mistura de argilominerais caulinita e montmorilonita, contendo também quartzo e sua morfologia lamelar. Entretanto, em função da significativa variação de granulometria entre estas, as mesmas devem ser homogeneizadas com outras matérias-primas de forma a garantir propriedades tecnológicas constantes.

Com base nos resultados obtidos através das análises, foi possível determinar as características de cada uma das argilas estudadas, podendo-se assim comprovar a importância de se ter um conhecimento adequado das matérias-primas e suas condições de uso na fabricação de produtos cerâmicos de qualidade.

Como sugestões para trabalhos futuros estão: verificar as características térmicas das argilas em questão por análise termogravimétrica e análise térmica diferencial - ATG/ATD, avaliar suas composições mineralógicas por difração de raios X DRX e realizar análise de área superficial específica segundo o método BET. 


\section{Referências}

Associação Brasileira De Cerâmica - ABCERAM (2021). Informações técnicas - definição e classificação. https://abceram.org.br/definicao-e-classificacao/ .

Associação Nacional Da Indústria Cerâmica - ANICER (2021). Dados do Setor. https://www.anicer.com.br/anicer/setor/ .

Bezerra, C. H. de A. (2012). Análise comparativa das propriedades físicas e mineralógicas dos depósitos de argila dos municípios de Crato e Jucás-CE. Dissertação de Mestrado. Programa de Pós-Graduação em Geologia, Universidade Federal do Ceará (UFC).

Caetano, E. H. (2015). Caracterização mineralógica de argilas bentoníticas. Dissertação de Mestrado. Programa de Pós-Graduação em Química Aplicada, Universidade Estadual de Ponta Grossa (UEPG), Ponta Grossa.

Carrera, A. M. M., Varajão, A. F. D. C. \& Gonçalves, M. A. (2008). Caracterização mineralógica das argilas da Península de Santa Elena, Equador. REM: Revista Escola de Minas, 61(1), 97-105.

Cartaxo, A. de S. et al. (2015). Caracterizações realizadas com argilas da região do Cariri - Ceará. In: Da Costa, C. T. F., Collares, R. L., Mota, D. A. R. \& De Oliveira, H. P. C. Caderno de Experiências: Pesquisa em Foco. Juazeiro do Norte, CE: Universidade Federal do Cariri. http://sites.ufca.edu.br/ebooks/wpcontent/uploads/sites/22/2015/11/Caderno-de-Experi\%C3\%AAncias-a-pesquisa-em-foco.pdf .

Dalfovo, M. S.; Lana, R. A. \& Silveira. (2008). Métodos qualitativos e quantitativos: um resgate teórico. Revista Interdisciplinar Científica Aplicada, 2 (4), 0113.

Dutra, R. P. D. et al. (2005). Estudo da variação da tonalidade de materiais cerâmicos tradicionais. Parte III: Efeito da composição química das argilas. Encontro Nacional de Tratamento de Minérios e Metalurgia Extrativa, Natal.

Ferreira, M. M. (2010). Caracterização de argilas cauliníticas do Quadrilátero Ferrífero visando seu potencial de aplicação na indústria de cerâmica. Dissertação de Mestrado. Programa de Pós-Graduação em Evolução Crustal e Recursos Naturais, Universidade Federal de Ouro Preto (UFOP), Ouro Preto.

Macêdo, R. J. F. et al. (2012). Caracterização dos resíduos das indústrias cerâmicas estruturais da região do Cariri - CE. Caderno de Cultura e Ciência, 11(2), $7-15$.

Maestrelli, S. C. et al. (2013). Estudo de caracterização de argilas não plásticas da região de Poços de Caldas, MG. Cerâmica, 59(350), 242-248.

Mariani, F. Q., Villalba, J. C. \& Anaissi, F. J. (2013). Caracterização estrutural de argilas utilizando DRX com luz síncronon, MEV, FTIR e TG-DTG-DTA. Orbital: The Eletronic Journal of Chemistry, 5(4), 249-256.

Menezes, R. R. et al. (2009). Argilas bentoníticas de Cubati, Paraíba, Brasil: Caracterização física-mineralógica. Cerâmica, 55(334), 163-169.

Moreno, M. M. T. (2010). Argilas e Argilominerais. DPM-IGCE-UNESP.

Neta, I. A. B. et al. (2016). Caracterização de argilas e massas utilizadas na indústria G MATOS de cerâmica vermelha na região do Cariri - Ceará. Congresso Brasileiro de Engenharia e Ciência dos Materiais, Natal, 21.

Oliveira, C. I. R. et al. (2016). Characterization of bentonite clays from Cubati, Paraiba (Northeast of Brazil). Cerâmica, 62(363), $272-277$.

Porto, J. P. P. \& Aranha, I. B. (2002). Caracterização cristaloquímica preliminar de bentonitas brasileiras. Jornada de Iniciação Científica, Rio de Janeiro. 10.

Prado, A. C. A. (2017). Projeto de Pesquisa: Diagnóstico ambiental e proposição de melhorias tecnológicas sustentáveis empregadas nas indústrias de cerâmica vermelha da região sul do estado do Ceará.

Reis, A. S. et al. (2014a). Caracterização de argila usada em massa de cerâmica vermelha. Congresso Brasileiro de Cerâmica, Bento Gonçalves: ABCERAM. 58 .

Reis, A. S. et al. (2014b) Estudo das características de argila para utilização em cerâmica estrutural. Congresso Brasileiro de Cerâmica, Bento Gonçalves: ABCERAM,. 58.

Riker, S. R. L. (2005). Argilas da região de Boa Vista - Roraima: mineralogia, geoquímica e aplicação tecnológica. Dissertação de Mestrado. Programa de Pós-Graduação em Geociências, Universidade Federal do Amazonas (UFAM), Manaus.

Rosetto, E. et al. (2009). Caracterização de argilas bentonitas e diatomitas e sua aplicação como adsorventes. Química Nova, 32(8), $2064-2067$.

Santos, P. S. (1989). Ciência e Tecnologia de Argilas. Edgar Blücher.

Silva, S. A. B. (2008). Estudos para a utilização dos argilominerais das jazidas de gipsita do Araripe-PE para produção de pigmentos naturais. Dissertação de Mestrado. Programa de Pós-Graduação em Química, Universidade Federal de Pernambuco (UFPE), Recife.

Silva, B. J. et al. (2011). Influência da taxa de aquecimento e da temperatura de queima sobre as propriedades de peças produzidas com massas da cerâmica vermelha. Congresso Brasileiro de Cerâmica. ABCERAM, 55.

Silva, S. V. \& Salvetti, A. R. Uso da espectroscopia infravermelha no estudo de argilas do Mato Grosso do Sul. Congresso Brasileiro de Cerâmica. Florianópolis: ABCERAM, 43.

Suassuna, P. M., Cartaxo, A. de S. \& Brasileiro, M. I. (2013) Caracterização de argilas utilizadas na indústria de cerâmica vermelha na região do Cariri - Ceará. Encontro Universitário da UFCA, Juazeiro do Norte: Universidade Federal do Cariri, 1.

Tonnensen, D. A. et al. (2012). Caracterização mineralógica e beneficiamento das bentonitas da região de Cubati e Pedra Lavrada - PB. Holos, 1, 2-14. 
Research, Society and Development, v. 10, n. 10, e448101018392, 2021

(CC BY 4.0) | ISSN 2525-3409 | DOI: http://dx.doi.org/10.33448/rsd-v10i10.18392

Vilar, W. C. T. et al. (2009). Ativação térmica e caracterização da argila chocolate visando sua aplicação como adsorvente na remoção de níquel. Revista Eletrônica de Materiais e Processos, 4(3), 39-47.

Zaccaron, A. (2018). Estudo do processo de secagem rápida em argilas utilizadas para fabricação de cerâmica vermelha. Dissertação de Mestrado. Programa de Pós-Graduação em Ciência e Engenharia de Materiais, Universidade do Extremo Sul Catarinense (UNESC), Criciúma. 